\title{
REDES COMERCIALES ENTRE LA ANDALUCÍA ATLÁNTICA Y LAS ISLAS CANARIAS A FINES DE LA EDAD MEDIA: UNA MIRADA A TRAVÉS DE LOS SIGS*
}

\author{
Enrique José Ruiz Pilares** \\ Universidad de Cádiz. Avda. \\ Daniel Ríos Toledano \\ Universidad de Cádiz
}

\begin{abstract}
Resumen
El presente artículo tiene como objetivo analizar las relaciones comerciales entre la Andalucía atlántica y el archipiélago canario a finales de la Edad Media. A partir de los contratos de fletamento andaluces y canarios se pretende perfilar algunas cuestiones sobre las redes mercantiles entre ambos ámbitos geográficos. El aspecto más novedoso de este trabajo es la incorporación de una detallada cartografía que permite conocer con más precisión la organización portuaria.
\end{abstract}

Palabras clave: Andalucía atlántica, archipiélago canario, contratos de fletamento, comercio, SIGs.

\author{
PORT NETWORKS BETWEEN THE ATLANTIC ANDALUSIA \\ AND THE CANARY ISLANDS IN THE LATE MIDDLE AGES: \\ A LOOK THROUGH THE GIS
}

\section{Abstract}

This main objective of this article is to analyse in detail the trade relations between the Atlantic Andalusia and the Canary Islands in the late Middle Ages. The main sources are the contracts of affreightment from both andalusians and canarians. From this study seeks to contribute to the knowlegde about the port networks. The most innovative of this paper is the incorporation of detailed cartography. This methodology allows us to go into the port organisation.

Keywords: Atlantic Andalusia, Canary Islands, Contracts of affreightment, Trade, GIS. 


\section{INTRODUCCIÓN}

Este trabajo se enmarca dentro de una línea de estudio dedicada a las actividades marítimas y comerciales en el Atlántico Medio durante la Baja Edad Media, que cuenta con una notable producción bibliográfica -monografías, artículos o actas de congresos- especialmente gracias a la enérgica labor del Grupo Castilla y el Mar en la Baja Edad Media de la Universidad de La Laguna.

El marco cronológico se centrará en las décadas comprendidas entre 14901520, período definido por la historiografía como de transición de la Edad Media a la Edad Moderna. Desde un punto de vista comercial, hasta esas fechas no se produce el desarrollo exponencial de las conexiones entre ambos mercados, tras la definitiva conquista castellana de todo el archipiélago en $1496^{2}$. Desde la perspectiva de las fuentes manejadas, los protocolos notariales sevillanos, jerezanos y tinerfeños ${ }^{3}$, aunque se constatan intercambios continuos entre ambos espacios desde la década de $1470^{4}$, habrá que esperar a finales de la centuria para contar con documentación más precisa: los contratos de fletamento 5 . Este tipo documental aporta una información muy

* Este trabajo forma parte del proyecto de investigación financiado por el Ministerio de Educación y que lleva por título «Solidaridad y/o exclusión en las fronteras marítimas. Castilla en la baja Edad Media» (referencia HAR2013-48433-c2-2-p).

** Grupo de Investigación PAIDI Medievalismo Gaditano.

${ }^{1} \mathrm{http}: / /$ www.castillayelmar.com. Sirva como referencia uno de los trabajos más citados al tratar este tipo de intercambios: AzNAR VALLEJO, Eduardo: «Las relaciones comerciales entre Andalucía y Canarias a finales del siglo Xv y comienzos del siglo XVI», en Hacienda y Comercio: Actas del II Coloquio de Historia Medieval Andaluza, Sevilla, 1982, 269-281.

2 Bello León, Juan Manuel: «El Reino de Sevilla en el comercio exterior castellano (siglos xiv y xv)", en Casado Alonso, Hilario (ed.): Castilla y Europa. Comercio y Mercaderes en los siglos XIV, XV y XVI, Burgos, 1995, 57-80, p. 68; Ladero Quesada, Miguel Ángel: «Los señores de Canarias en su contexto sevillano (1403-1477)", Anuario de Estudios Atlánticos, 24, 1997, 125-164.

3 Sobre este tipo de fuentes véase Muñoz Gómez, Víctor, Bello León, Juan Manuel, y GonZÁlez Zalacaín, Roberto J.: «Nuevas propuestas con viejas fuentes: la documentación para el estudio de los puertos andaluces en la Época de los Descubrimientos», en XX Coloquio de Historia Canario Americana. Homenaje a Francisco Morales Padrón. Sevilla-Canarias-América. El Atlántico como espacio encuentro, Las Palmas de Gran Canaria, 2014, 180-192.

${ }^{4}$ Ladero Quesada, Miguel Ángel: «Las cuentas de la conquista de Gran Canaria», Anuario de Estudios Atlánticos, 12, 1961, 11-104, en especial pp. 44-45; OtTe Sander, Enrique: Sevilla y sus mercaderes a fines de la Edad Media, Sevilla, 1996; y Mingorance Ruiz, José Antonio, Los extranjeros en Jerez de la Frontera a fines de la Edad Media, Sevilla, 2013, http://hdl.handle.net/10433/755.

5 Para el análisis de los fletes jerezanos contamos con los siguientes trabajos: MarTín Gutiérrez, Emilio: «La participación de Jerez de la Frontera en los circuitos comerciales atlánticos a finales de la Edad Media: los contratos de fletamientos», en González Jiménez, Manuel y Montes Romero-Camacho, Isabel (coords.): La Peninsula Ibérica entre el Mediterráneo y el Atlántico. Siglos XIII-XV, Cádiz-Sevilla, 133-141; Ruiz Pilares, Enrique José: «Las relaciones comerciales entre Canarias y la Bahía de Cádiz tras la conquista del archipiélago. Una aproximación a partir de la documentación notarial jerezano", en Aznar Vallejo, Eduardo, Rodríguez, Gerardo, Zapatero, Mariana y MuÑoz Gómez, Víctor (coords.): Sentir América: Percibiry construir las fronteras castellanas (c. 1300-c. 1600), Buenos Aires, en prensa. Para el caso hispalense, nos remitimos a OTte SANder, Enrique: Sevilla y sus mercaderes, op. cit. De igual forma, para los canarios nos remitimos al estudio 
valiosa para conocer con mayor profundidad el mundo mercantil medieval: puerto de salida y de destino, tipo de embarcación, mercancía, propietario, maestre, etc ${ }^{6}$.

La propuesta más novedosa de este estudio es la incorporación de una detallada cartografía que plasma los datos aportados en nuestro estudio. Las representaciones gráficas de las redes comerciales y portuarias han brillado por su ausencia en el ámbito de la historia medieval española. Aunque disponemos de algunas monografías de referencia que ilustran este tráfico mercantil ${ }^{7}$, es necesario insistir en la importancia de incorporar cartografías que representen el espacio de manera mucho más precisa y cuidadosa con los cambios generados en el medio natural con el transcurso de los siglos. Para avanzar en esta dirección es fundamental aportar proyecciones del espacio fluviomarítimo generados y procesados a partir de las nuevas tecnologías, como son los Sistemas de Información Geográfica. Estas herramientas nos permiten aproximarnos a la reconstrucción de la paleocosta y paleocauces en épocas históricas, como puede observarse en la dilatada bibliografía generada por el Seminario Agustín de Horozco de Estudios Económicos de Historia Antigua y Medieval de la Universidad de Cádiz en la última década ${ }^{8}$.

\section{LAS CONEXIONES PORTUARIAS A TRAVÉS DE LOS FLETAMENTOS ANDALUCES}

El primer contrato de flete registrado en Sevilla con destino a Canarias está fechado en 1496. Un documento tardío, si tenemos en cuenta las referencias indirectas a exportaciones que recorren la documentación notarial hispalense como mínimo desde 1472. A finales del siglo xv el archipiélago se había convertido en uno de los destinos principales de las embarcaciones que partían de esta ciudad -en un

de Bello León, Juan Manuel y González Marrero, María del Cristo: «Los «otros extranjeros»: catalanes, flamencos, franceses e ingleses en la sociedad canaria de los siglos XV y XVI», Revista de Historia Canaria, 179, 1997, 11-72; 180, 1998, 13-68.

6 Martín Gijón, José, «La práctica del fletamento de mercancías con las Indias (siglo XVI)», Historia, Instituciones, Documentos, 10, 1983, 119-155.

7 Aznar Vallejo, Eduardo y González Zalacaín, Roberto J. (coords.): De mar a mar. Los puertos castellanos en la Baja Edad Media, La Laguna, 2015. Asimismo, debemos destacar las representaciones que acompañan los trabajos de Michel BocHACA, como en su reciente trabajo sobre la costa andaluza con Enrique José Ruiz Pilares, «Un exemple de relations commerciales entre le pays de León et l'Andalousie au debut du XVI ${ }^{\mathrm{e}}$ siécle, d'après le compte d'un marchand de Morlaix», Annales de Bretagne et des Pays de l'Ouest, 123/4, 2016, 7-34.

${ }^{8}$ En el marco del medievo debemos destacar Martín Gutiérrez, Emilio: «Interacción sociedad medio ambiente. El entorno de la laguna de los Tollos (Andalucía Occidental). Siglos XIII al XV», Studia Histórica: Historia Medieval, 32, 2014, 103-130; y Ruiz Pilares, Enrique José: «La sociedad jerezana y su implicación en las actividades comerciales. La producción y la comercialización del vino. (finales s. Xv-inicios s. Xvi)». En Solórzano Telechea, Jesús Ángel, Arízaga Bolumburu, Beatriz, y Bochaca, Michel (coords.): Las sociedades portuarias de la Europa Atlántica en la Edad Media, Logrońo, 2016, 337-364. 


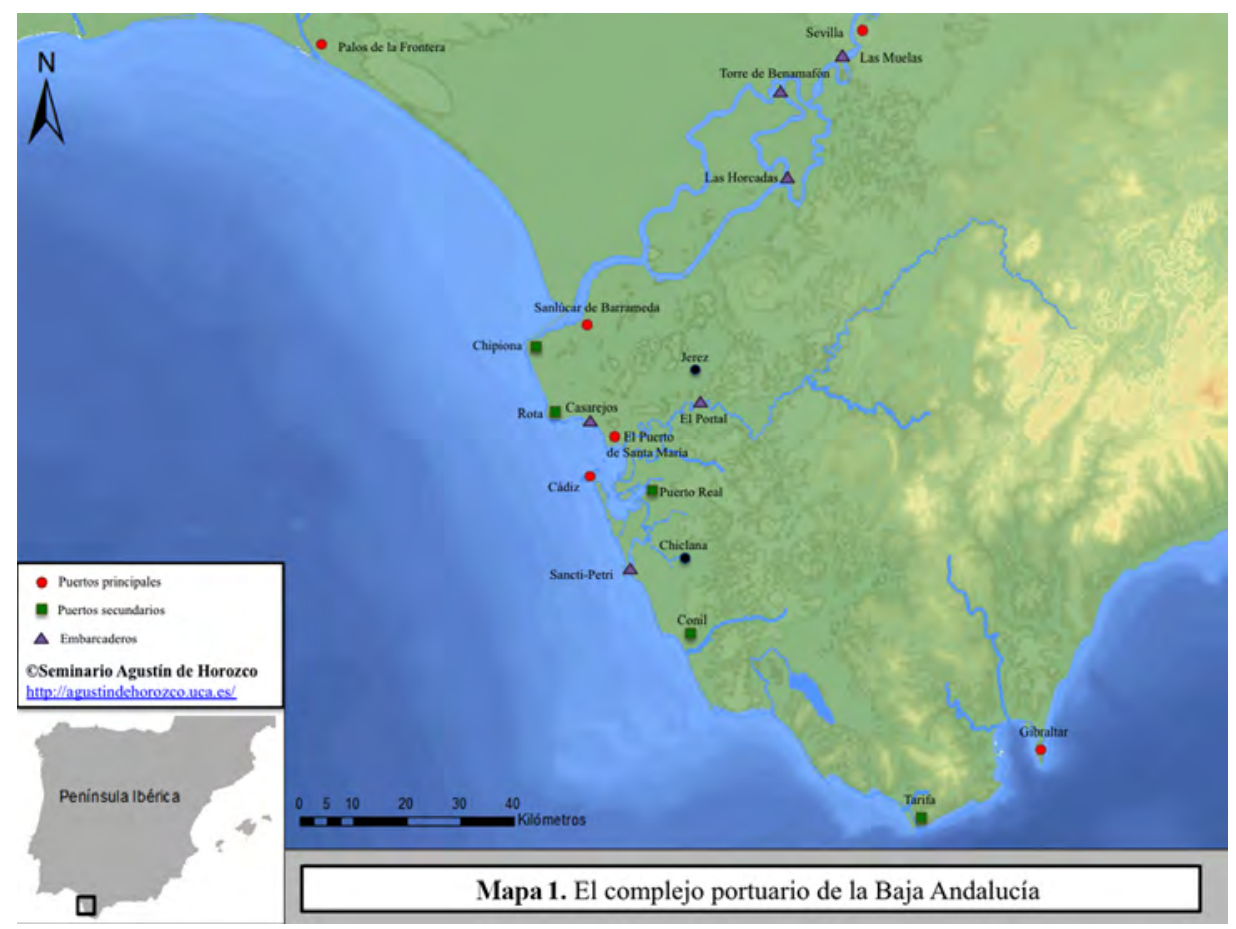

Mapa 1. El complejo portuario de la Baja Andalucía.

$21 \%$ de los fletes documentados entre 1496 y $1512^{9}-$, ya fuese directamente desde el muelle de las Muelas ${ }^{10}$, situado en el tramo del Guadalquivir que circulaba por la localidad, o a partir de toda una serie de embarcaderos menores situados en el transcurso de este río hasta Sanlúcar de Barrameda (mapa 1) ${ }^{11}$. Entre ellos destacaba el muelle de las Horcadas, un surgidero a medio camino entre la ciudad y la costa donde se podían cargar las embarcaciones con mayor tonelaje (cuadro I) ${ }^{12}$.

${ }^{9}$ Otte Sander, Enrique: Sevilla y sus mercaderes..., op. cit., p. 123.

${ }^{10}$ González Jiménez, Manuel y Bello León, Juan Manuel: «El puerto de Sevilla en la Baja Edad Media (siglos XIII-Xv)», en Abulafia, David y Garí, Blanca (coords.): En las costas del Mediterráneo oriental: las ciudades de la Peninsula Ibérica y del reino de Mallorca y el comercio mediterráneo en la Edad Media, Barcelona, 1996, 213-237.

${ }_{11}$ Para la elaboración de esta cartografía ha sido necesaria la consulta de los repositorios digitales de la Junta de Andalucía <http://www.ideandalucia.es/> y el material elaborado en los últimos años en el Seminario Agustín de Horozco <http://agustindehorozco.uca.es/>.

12 Otte SAnder, Enrique: Sevilla, siglo XVI: Materiales para su historia económica: materiales para su Historia Económica, Sevilla, 2008, p. 133. 


\begin{tabular}{lccc}
\hline \multicolumn{4}{c}{ CUADRO I. PUERTOS DE SALIDA Y LLEGADA EN LOS FLETAMENTOS } \\
CONCERTADOS EN SEVILLA Y JEREZ
\end{tabular}

* Nos remitimos a las referencias aportadas en la nota 5 .

En el caso de Jerez, los primeros fletes conservados con destino a Canarias datan de 1514. A pesar de que esta ciudad contaba con diferentes embarcaderos fluviales en el río Guadalete -principalmente en la aldea de El Portal-, sus infraestructuras -tantos fluviales como terrestres ${ }^{13}$ - eran bastante precarias, dificultando la carga de mercancías en embarcaciones de cierto porte ${ }^{14}$. Por este motivo, los mercaderes locales concertaban sus negocios en la Bahía de Cádiz, ya fuese en la propia Cádiz o en El Puerto de Santa María, donde residían los maestres de las embarcaciones de mediano y gran tamańo, como carabelas y naos ${ }^{15}$. Hasta la construcción de un muelle en El Portal, en torno a 1510-1512, los operadores jerezanos conectaban el Guadalete con la Bahía a través de pequeñas barcas ${ }^{16}$. A partir de esa fecha, empiezan a aparecer contratos de flete que tienen como punto de partida el mencionado

13 Ruiz Pilares, Enrique José: «La política viaria municipal a finales de la Edad Media (1430-1530): el caso de Jerez de la Frontera», Norba. Revista de Historia, 25/26, 2012-2013, 207-226.

${ }^{14}$ Ello explica, entre otros motivos, su ausencia en los derroteros de navegación, MuÑoz Gómez, Víctor: «Para el conocimiento de la costa de Andalucía atlántica (siglos XIV-XVI), descripciones, relaciones y documentación náutica», Historia. Instituciones. Documentos, 40 (2013), 179-205.

${ }^{15}$ El funcionamiento de este complejo portuario gaditano ha sido estudiado recientemente por González Zalacaín, Roberto J.: «De Puerto a Puerto. Las relaciones entre los puertos de la Bahía de Cádiz (Siglos XV-XVI)», en Aznar Vallejo, Eduardo y González Zalacaín, Roberto J. (coords.): De mar a mar, op. cit., pp. 147-177.

${ }^{16}$ La construcción del muelle y sus pormenores han sido tratadas en Ruiz Pilares, Enrique José: «Las relaciones comerciales...», op. cit., en prensa. 
emplazamiento ${ }^{17}$. Entre 1514 y 1520 , el archipiélago se menciona en el 20\% de los 81 fletes documentados ${ }^{18}$. Un porcentaje idéntico al sevillano para esos años, según el dato ya adelantado. Ello no significó que a partir de ese momento todas las embarcaciones partiesen desde El Portal: en el caso de Canarias solo aconteció así en el $50 \%$ de los casos, partiendo el resto desde alguna localidad de la bahía (cuadro I) ${ }^{19}$.

El destino principal de las embarcaciones que partieron desde Jerez y Sevilla fue el puerto de Las Isletas o Puerto Real de la isla de Gran Canaria. Aparece en el $100 \%$ de los negocios: en el $62 \%$ como destino único en el caso jerezano, descendiendo al $12 \%$ en el caso de Sevilla. En alguna ocasión también se menciona una pequeña parada en embarcaderos cercanos como el puerto de las Sardinas, La Caleta, la ermita de Santa Catalina, Melenara o Telde (mapa 2) ${ }^{20}$. No obstante, en algunos acuerdos se solían pactar destinos secundarios o alternativos - principalmente Tenerife y sus embarcaderos subsidiarios- si los precios alcanzados en el primer mercado no resultaban atractivos a los mercaderes (cuadro I) ${ }^{21}$. En ocasiones también se realizaba en una primera etapa en enclaves comerciales norteafricanos -como Safí o el Cabo de Aguer- para vender o trocar mercancías antes de dirigirse a las Canarias ${ }^{22}$.

Respecto a los productos, el vino aparece en el $57 \%$ de las embarcaciones que parten desde Sevilla, seguido a mucha distancia por manufacturas como la loza $-21 \%$-, siendo el resto de las mercancías menos relevantes -aceite, bizcocho, carne, cereales o esclavos ${ }^{23}-$. En el caso jerezano, con un mercado mucho menos dinámico, las exportaciones se limitaron casi exclusivamente a dos, el vino $-80 \%-$ y el trigo

${ }_{17}$ En los protocolos hispalenses aparecen ocho embarcaciones que recibieron carga en El Portal en este mismo contexto, Otte Sander, Enrique: Sevilla y sus mercaderes..., op. cit., pp. 251255 y $262-263$.

${ }_{18}$ Ruiz Pilares, Enrique José: «Las relaciones comerciales...», op. cit., en prensa.

19 En un caso singular desde varios puertos de la zona: en 1519 el maestre portugués Benito Lorenzo recibió «en la Baya de la villa de Chipiona treynta botas, e dos botas en la Baya de Rota, e vna bota en Casarejos, e las otras botas restantes [procedentes de Jerez vía Guadalete] en la Baya de la çibdad de Cádiz», Martín Gutiérrez, Emilio: «La participación...», op. cit., p. 136.

${ }^{20}$ Las referencias a estos embarcaderos proceden de Bello León, Juan Manuel y GonzÁlez Marrero, M. ${ }^{a}$ del Cristo: «Los otros...», op. cit., v. 179, pp. 53-54; OtTe SAnder, Enrique: Sevilla..., op. cit., pp. 234-263; y López García, Juan Sebastián: «El Puerto de Sardina de Gáldar en los siglos Xv y XVI», en Morales Padrón, Francisco (coord.): V Coloquio de Historia CanarioAmericana, 2, 1985, 421-434. Como base para la elaboración de la cartografía del archipiélago canario se ha consultado su repositorio de cartografía digital https://www.idecanarias.es/ y Tous MeLía, Juan: Las Islas Canarias a través de la Cartografía: Una selecciión de los mapas más emblemáticos levantados entre 1507 y 1898, Islas Canarias, 2014.

${ }^{21}$ Así lo acordó el jerezano Alonso Gil de la Barca con el maestre portuense Pedro Sánchez: «sy no quisieredes descargar en el dicho puerto de las Ysletas los dichos vinos e las otras mercaderías que cargaredes en la dicha mi nao, que yo sea obligado, pasado el dicho tercer día de partir [...] e seguir hasta la dicha ysla de Tenerife», AMJF, PN, 1514, escribano Luis de Llanos, fols. 11136v-1138r.

22 Para conocer los trayectos completos y sus diferentes conexiones o alternativas véase Ruiz Pilares, Enrique José, «Las relaciones...», op. cit., en prensa, y Otte Sander, Enrique: Sevilla y sus mercaderes..., op. cit., pp. 124, 153 y 234-245.

${ }^{23}$ Otte Sander, Enrique: Sevilla..., op. cit., p. 69. 


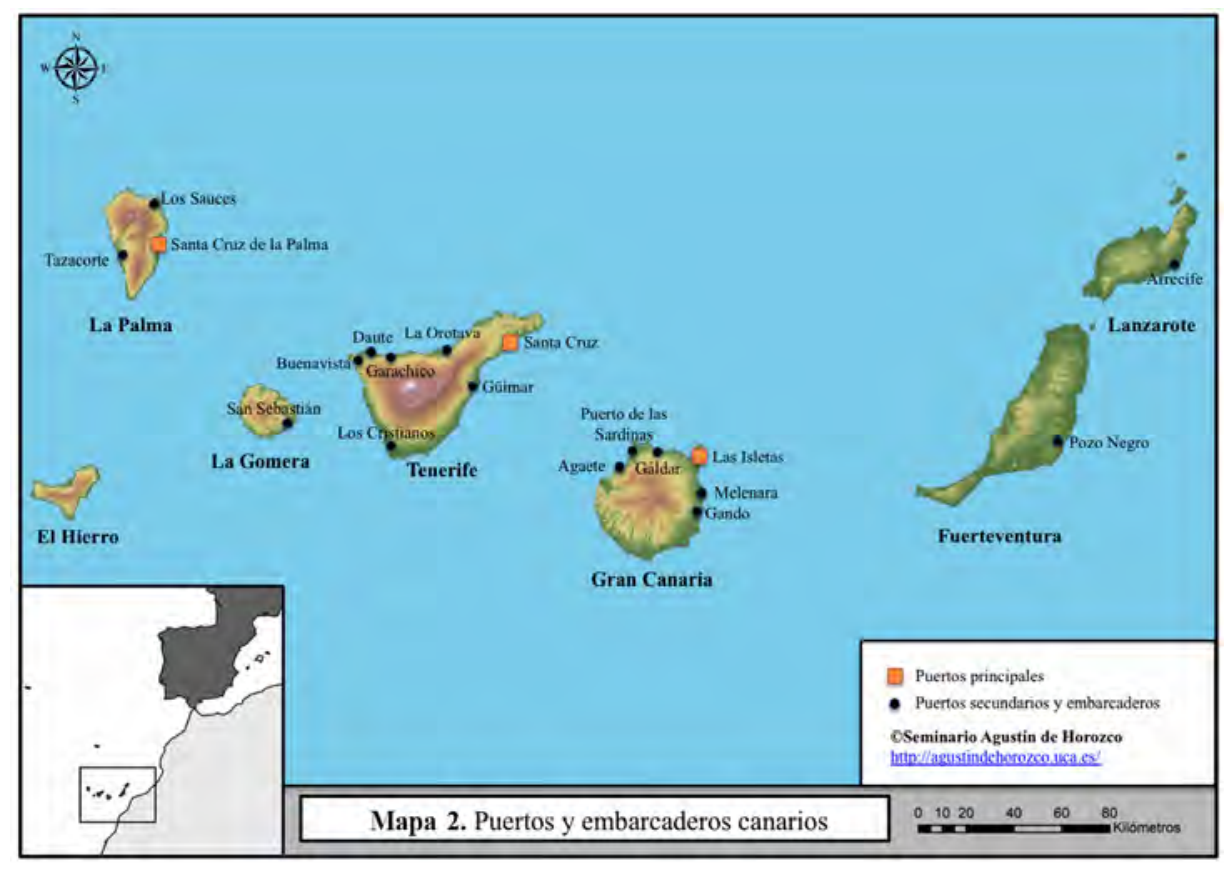

Mapa 2. Puertos y embarcaderos canarios.

$-20 \%-$, siendo insignificantes las referencias a otros productos ${ }^{24}$. No nos extraña el protagonismo de los caldos andaluces en Canarias, como ocurría en los mercados del Atlántico Norte, ya que en esas fechas se había convertido en el producto andaluz más cotizado en los mercados europeos ${ }^{25}$. En contrapartida, el cereal no parece que fuese tan necesario en Canarias a comienzos del siglo xvi como en tiempos de la conquista ${ }^{26}$.

${ }^{24}$ Sobre la importancia de este cultivo, en alza a finales del siglo xv, véase Martín Gutiérrez, Emilio: «El viñedo en la zona de Jerez a finales de la Edad Media», en Malpica Cuello, Antonio, Peinado Santaella, Rafael G. y Fábregas García, Adela (eds.): Historia de Andalucía. VII Coloquio, Granada, Universidad de Granada, 2009, 287-300. La población, desde los campesinos a los terratenientes, se implicaron de lleno en sus procesos de producción y exportación, RuIz Pilares, Enrique José: «La sociedad jerezana...», op. cit., pp. 337-364.

${ }_{25}$ Una síntesis sobre el comercio andaluz en Aznar Vallejo, Eduardo, «Andalucía y el Atlántico Norte a fines de la Edad Media», Historia. Instituciones. Documentos, 30 (2003), 103-120.

${ }^{26}$ Sobre este producto véase Martín Gutiérrez, Emilio, La organización del paisaje rural en la Baja Edad Media, Sevilla, Universidad de Cádiz-Universidad de Sevilla, 2004, pp. 51-53. 
Los contratos de flete, tanto en Sevilla como en Jerez, fueron estipulados en su práctica totalidad por comerciantes castellanos. El protagonismo en Sevilla recayó en los vecinos de esa ciudad -un 69,5\% entre los que se encontraban dos ligures ya avecindados-, frente a un $21,5 \%$ que procedían del archipiélago canario $-13 \%$ de Gran Canaria y 8,5\% de Tenerife- y un 8,5\% de la villa de Palos de la Frontera ${ }^{27}$. Por su parte, en Jerez el predominio absoluto era de los operadores locales ${ }^{28}$. Aunque sabemos que la participación de los extranjeros en el comercio con Canarias fue importante, su práctica ausencia en la documentación notarial debe explicarse, en gran medida, en el hecho de que eran propietarios de sus propios navíos, como ha podido documentarse en el caso de compañías italianas o bretonas que operaban en la Bahía de Cádiz ${ }^{29}$.

Respecto al transporte de las mercancías, esta actividad contó con la participación de maestres de orígenes muy diversos. En los contratos sevillanos más del $80 \%$ eran vecinos con toda probabilidad del barrio de Triana ${ }^{30}$. El resto procedían de la mencionada villa marinera de Palos. En el caso de Jerez, la flota procedía esencialmente de la región portuguesa del Algarve $-43 \%-$, con una presencia muy importante en la región ${ }^{31}$, de la localidad gaditana de El Puerto de Santa María $-32 \%{ }^{32}-$, y en menor medida de Cádiz y Sevilla $-12,5 \%$ cada una, respectivamente-. La ausencia de maestres de navíos entre los vecinos de Jerez se explica por su situación en el interior de la comarca gaditana, ya mencionada. Estos, a su llegada al archipiélago canario, solían entrar al servicio de los comerciantes de las islas, al menos así se ha constatado en el caso de los portugueses ${ }^{33}$. Los lusos se convirtieron en los principales transportistas del primer tercio del siglo $\mathrm{XVI}^{34}$.

27 Otte SAnder, Enrique: Sevilla y sus mercaderes..., op. cit., p. 69.

${ }^{28}$ Ruiz Pilares, Enrique José: «"Las relaciones comerciales...», op. cit., en prensa. Véanse estas cuestiones en Martín Gutiérrez, Emilio: «El memorial de bienes y deudas de Diego de Lepe (1517). A propósito del sistema crediticio en Jerez de la Frontera», Historia. Instituciones. Documentos (2017), en prensa.

${ }^{29}$ Mingorance Ruiz, José Antonio: Extranjeros en Jerez..., op. cit., pp. 654-2056. Un caso muy interesante sobre este tipo de compañías se ha reconstruido a partir de las fuentes bretonas en Ruiz Pilares, Enrique José y Bochaca, Michel: «Un exemple de relations...», op. cit., pp. 7-34.

30 Otte SAnder, Enrique: Sevilla y sus mercaderes..., op. cit., pp. 113-114.

31 Baquero Moreno, Humberto: «Relaçes relaçóes e comerciais entre Portugal e Baixa Andaluzia nos séculos XIV e XV", Estudios de Historia y Arqueología Medievales, X (1994), 25-40; Mingorance Ruiz, José Antonio: Extranjeros en Jerez..., op. cit., pp. 159-162.

32 Sobre la flota portuense véase Franco Silva, Alfonso: «Los pescadores del Puerto de Santa María y sus problemas a comienzos del siglo xvi», Historia. Instituciones. Documentos, 22, 1994, pp. 191-214.

${ }^{33}$ Es el caso de los maestres Cristóbal Díaz o Jorge González, documentados en fletes concertados en ambos espacios, Ruiz Pilares, Enrique José: ««Las relaciones comerciales...», op. cit., en prensa.

${ }^{34}$ Más del 70\% de los maestres con naturaleza conocida eran de origen portugués. Así se desprende de un amplio elenco de fletes fechado entre 1506 y 1531, Ibidem. Sobre la comunidad lusitana en las islas véase Bello León, Juan Manuel: «Una aproximación a los estudios sobre relaciones entre Canarias y Portugal a finales de la Edad Media». En Adao da Fonseca, Luis, Amaral, Luis y Ferreira Santos, María Fernanda (eds.): Os Reinos ibéricos na Idade Média. Livro de Homenagem 
Los portugueses optaban por la carabela $-90 \%$ de los casos-, que remontaba bien el Guadalete para llegar al Portal, embarcación ligera muy habitual para los trayectos del Atlántico Medio. Por su parte, los maestres de la Bahía de Cádiz, Palos y Sevilla eran en su mayor parte propietarios de embarcaciones de mayor tonelaje, como las naos y los navíos, que solían esperar su mercancía en la Bahía, ensenada por excelencia del comercio gaditano ${ }^{35}$. No obstante, más allá de su tipología y envergadura, las embarcaciones que partieron desde Jerez con destino a Canarias contaban con una media reducida, especialmente en el caso de las naos, que rondaba entre las 30 y las 50 toneladas $^{36}$.

\section{LAS CONEXIONES PORTUARIAS A TRAVÉS DE LOS FLETAMENTOS CANARIOS}

El tráfico comercial entre Canarias y los puertos marítimos de la Baja Andalucía fueron intensos desde finales del siglo Xv, como acabamos de mencionar. En torno a este período, un viaje con destino a las islas solía durar aproximadamente de siete a ocho días, como queda manifestado en el segundo viaje de Colón en su trayecto entre Cádiz y Canarias en $1493^{37}$. El archipiélago disponía de un elenco de enclaves naturales con posibilidades para fondear y descargar. Estos centros portuarios constituían una tupida red perfectamente conectada entre sí y con el exterior. Tenerife contaba con el puerto de Santa Cruz y varios embarcaderos de menor entidad como Garachico. En la isla de Gran Canaria su fondeadero principal se localizaba en Las Isletas, aunque también se han documentado en Melenara o Las Sardinas. La misma realidad se observa en el resto de las islas (mapa 2).

De los contratos de fletamento entre Canarias y Andalucía se desprende que el azúcar y la orchilla fueron la principal exportación, productos altamente demandados en los mercados europeos que estuvieron muy monopolizados por los genoveses y, en menor medida, por los catalanes ${ }^{38}$. Dentro de este tráfico comercial

ao Professor Doutor Humberto Carlos Baquero Moreno, Oporto, v. 1, 2003, 737-742 y Martín Socas, Margarita: «Sobre los oficios desempeńados por los portugueses establecidos en Canarias en el primer cuarto del siglo XVI», en el VII Coloquio de historia canario-americano, Las Palmas, Cabildo Insular de Gran Canaria, 59-75.

35 Una síntesis sobre estos navíos en Aznar Vallejo, Eduardo: «La experiencia marítima: las rutas y lo hombres del mar», en V.V.A.A., Andalucía 1492: razones de un protagonismo, Sevilla, 1992, pp. 123-156.

${ }^{36}$ Sobre la tonelada, medida de referencia para toda Europa, véase Martíns Viana, Mario Paulo: «Sociedades portuárias e técnicas mercantis. A metrología do transporte marítimo (seculos XIVxv)", en Arízaga Bolumburu, Beatriz y Solórzano Telechea, Jesús Ângel (coords.): Las sociedades portuarias, op. cit., pp. 319-336.

37 Colón, Cristóbal: Diario de navegación y otros escritos. Estudios preliminares de Balaguer, Joaquín, Menéndez Pidal, Ramón y Deive, Carlos Esteban, Santo Domingo, 1988, p. 356.

${ }_{38}$ Macías Hernández, Antonio Manuel: «Canarias. 1480-1550: Azúcares y crecimiento económico», en Vieira, Alberto (ed.), Histórica do Açúcar. Rotas e mercados, Funchal, 2002, 157-191; 
es preciso destacar las exportaciones de maderas -cajas y tablas-y la pez, material imprescindible para la construcción naval ${ }^{39}$. Por su parte, el trato de indígenas fue frecuente a lo largo del siglo xv, aunque desapareció progresivamente tras la promulgación de una serie de leyes por parte de los Reyes Católicos que prohibían la esclavitud de los canarios ${ }^{40}$.

Referente a la tipología naval, en la navegación atlántica predominaron los barcos veleros, como ya se ha mencionado al hablar de las embarcaciones que partían del reino de Sevilla. En el caso de los maestres, los escasos fletes conservados en el archivo tinerfeño para comienzos del siglo XVI ponen de manifiesto el mismo protagonismo de sevillanos, portugueses y gaditanos, aunque aparecen otros profesionales como los genoveses, cuyo protagonismo ya hemos señalado ${ }^{41}$.

Cádiz fue el principal puerto de destino. Esta ciudad disponía de un puerto con una estratégica posición geográfica y con posibilidades favorables para el atraque (mapa 1). Este hecho favoreció notablemente el desarrollo de su actividad comercial marítima como centro de consumo y redistribuidor -tanto al interior como a los cotizados mercados de Flandes, Italia o Inglaterra- del complejo portuario de la Baja Andalucía ${ }^{42}$.

\section{CONCLUSIONES}

Las conexiones portuarias entre ambos mercados eran ya frecuentes y sólidas a comienzos del siglo XVi. A pesar de la pérdida de documentación, especialmente para las dos ciudades portuarias más importantes en este tránsito comercial -Las Palmas y Cádiz-, los registros notariales hispalenses, jerezanos y tinerfeños nos permiten reconstruir con bastante nitidez la naturaleza de estos intercambios. Las Palmas de Gran Canaria era el principal foco receptor y redistribuidor de las mercaderías que llegaban al archipiélago. Este mismo papel jugaba Cádiz para los productos

\footnotetext{
Viña Brito, Ana (ed.): Azúcar y mecenazgo en Gran Canaria. El oro de las Islas, siglos XV-XVI, Las Palmas de Gran Canaria, 2014; Bello León, Juan Manuel: «Contribución a la biografía del mercader genovés Francisco Riberol [1458-1514]», en Rodríguez Morales, Carlos (coord.): La torre: Homenaje a Emilio Alfaro Hardisson, La Laguna, 2005, 123-144M. Idem: «La presencia catalana en la Andalucía Occidental a finales de la Edad Media", Anuario de estudios medievales, 40/1, 2010, 93-127.

39 Aznar Vallejo, Eduardo: «Productos y mercados atlánticos en el desarrollo económico andaluz del Siglo XV», en Cavaciocchi, Simonetta: Prodotti e tecniche d'Oltremare nelle economie europee secc. XIII-XVIII, Florencia, 439-449.

40 Franco Silva, Alfonso: La esclavitud en Sevilla y su tierra, Sevilla, 1979, pp. 59-104; Abril Fuertes, José María y Mingorance Ruiz, José Antonio: La esclavituden la Baja Edad Media: Jerez de la Frontera, 1392-1550, Jerez de la Frontera, 2014; Lobo Cabrera, Manuel: «La esclavitud del indígena canario», El Museo Canario, 55, 2000, 125-138.

41 Bello León, Juan Manuel y González Marrero, María del Cristo: «Los otros...», op. cit., 179, 1997, pp. 52-53.

42 Ríos Toledano, Daniel: «El puerto de Cádiz en la Baja Edad Media: una introducción a su estudio", en prensa.
} 
que llegaban a Andalucía desde Canarias, como ya había puesto de manifiesto la historiografía. La nao, en el caso de la flota castellana, y la carabela, para los lusos, eran las embarcaciones habituales en estos trayectos según los fletes concertados. Respecto a los exportadores, los lugareños, tanto en Andalucía como Canarias, fueron los principales protagonistas de los contratos conservados. No obstante, el protagonismo de los genoveses debió ser bastante alto, a tenor de su interés y control de la producción del azúcar y la orchilla.

La cartografía incorporada nos permite situar con mayor claridad la información aportada por las fuentes documentales, aproximándonos con mayor rigor al funcionamiento del complejo portuario de ambos mercados. En el mapa de la costa andaluza, debido a la experiencia atesorada por el Seminario Agustín de Horozco en este tipo de material gráfico, se ha profundizado con mayor precisión en la reconstrucción de la paleocosta y paleocauces, como hemos observado en las amplias variaciones existentes entre las vertientes de los actuales ríos Guadalete y Guadalquivir y los representados en el mapa 1.

ReCiBido: 14-03-2018, ACEPTADo: 10-04-2018 
